\title{
Gênero e sexualidade na formação docente em Cocalinho-MT: um estudo crítico do discurso
}

\author{
Márcio Evaristo Beltrãa \\ Doutorando em Estudos de Linguagem \\ Programa de Pós-Graduação em Estudos da Linguagem/ \\ UFMT \\ Solange Maria de Barros \\ Programa de Pós-Graduação em Estudos da Linguagem/ \\ UFMT
}

Resumo: Neste trabalho, propomos analisar, por meio da categoria de significado representacional do discurso e da transitividade dos processos, enunciados (discursos) proferidos por um docente da rede estadual de ensino de Mato Grosso e um mecânico heterossexual do gênero feminino, ambos da cidade de Cocalinho-MT. O objetivo da análise é identificar quais discursos dialogam nas instâncias discursivas dos dois participantes acerca de questões relacionadas a gênero e sexualidade, além de compreender em que medida a reflexão crítica, em cursos de formação continuada, contribui para a desestabilização de percepções de mundo naturalizadas. Como instrumento metodológico, são utilizadas a Análise Crítica do Discurso (FAIRCLOUGH, 2003a), por meio da categoria analítica interdiscursividade, e a Linguística Sistêmico-Funcional, de Halliday (1994). Os resultados obtidos apontam que o curso sobre diversidades contribuiu para desestabilizar posicionamentos legitimados do docente participante da pesquisa, relacionados à identidade sexual e de gênero. Verificamos que a interação com um indivíduo que não segue o que é legitimado na concepção heteronormativa contribuiu para que professor refletisse sobre questões de gênero e sexualidade.

Palavras-chave: Gênero e sexualidade; Análise Crítica do Discurso; Formação crítico-reflexiva. 


\title{
Gender and sexuality on teacher formation in Cocalinho- MT: a critical study of discourse
}

\begin{abstract}
In this paper, we propose to analyze, through the category of representational meaning of discourses and transitivity processes, utterances (discourses) from a teacher who work for the public system of education of Mato Grosso and a heterosexual mechanical of female gender, both the city of Cocalinho-MT. The objective of the analysis is to identify which discourses dialogue in the discursive instances of the two participants on issues related to gender and sexuality, as well as to understand the extent to which critical reflection in continuing education courses, contributes to the destabilization of naturalized perceptions of the world. As a methodological instrument, this study used Critical Discourse Analysis (FAIRCLOUGH, 2003a), through an analytical category interdiscursivity and Systemic Functional Linguistics by Halliday (1994). The results suggest that the course about diversity contributed to destabilize legitimate positions of the research participant about sexual identity and gender. We found that the interaction with an individual who does not follow what is legitimized in heteronormative conception contributed to teacher reflect on gender and sexuality issues.
\end{abstract}

Keywords: Gender and sexuality; Critical Discourse Analysis, Critical Teacher Formation.

\section{Género y sexualidad en la formación docente en Cocalinho-MT: un estudio crítico del discurso}

Resúmen: En este trabajo, proponemos analizar por medio de la categoría del significado representacional del discurso y de la transitividad de los procesos, enunciados (discursos) proferidos por un docente de la red estadual de enseño de Mato Grosso y un mecánico heterosexuale del género femenino, los dos de la ciudad de Cocalinho-MT. El objetivo de la análisis es identificar cuáles son los discursos que dialogan en las instancias discursivas de los dos participantes acerca de las cuestiones relacionadas al género y la sexualidad, allá de comprender en qué medida la reflexión crítica, en cursos de formación continuada, contribuye para la desestabilización de las percepciones de mundo naturalizadas. Como instrumento metodológicos, son utilizadas la Análisis Crítica del Discurso (FAIRCLOUGH, 2003a), por medio de la categoria analitica interdiscursividad, y la lingüística sistémico-funcional, del Halliday (1994). Los resultados obtenidos muestran que el curso sobre las diversidades contribuye para desestabilizar posicionamento legitimados del docente participante de la pesquisa, relacionados a la identidad sexual y del género. Verificamos que la interacción con el individuo que no sigue lo que es legitimado en la concepción heteronormativa contribuyeron para que el profesor reflexione sobre las cuestiones del género y sexualidad. 
Palabras-clave: Género y Sexualidad; Análisis Crítica del Discurso; Educación crítica-reflexiva.

Este artigo propõe analisar os enunciados de um docente da rede pública de ensino do Estado de Mato Grosso acerca de questões relacionadas a gênero e sexualidade e de um mecânico heterossexual do gênero feminino, ambos da cidade de Cocalinho-MT. O objetivo do trabalho é identificar quais discursos dialogam em suas práticas discursivas por meio do arcabouço teórico da Análise Crítica do Discurso (FAIRCLOUGH, 2003a) e da Linguística SistêmicoFuncional de Halliday (1994). Os dados foram coletados durante um curso de formação contínua sobre diversidades e em entrevistas semiestruturadas realizada ao fim dele.

As seções deste trabalho estão divididas em seis etapas. Inicialmente, apresentamos breves conceituações acerca de gênero e sexualidade. Em seguida, tecemos considerações sobre a abordagem teórica da análise crítica do discurso e da linguística sistêmico-funcional. Na sessão seguinte, discorremos sobre a reflexão na prática docente. Expomos a contextualização da pesquisa, a análise de dados e, por fim, as considerações finais.

\section{Gênero e sexualidade}

A diferenciação entre os conceitos de sexo, gênero e sexualidade é considerada um debate constante. Louro (1997) argumenta que foi por meio das feministas anglo-saxãs que o termo gender passou a ser utilizado como distinto do termo sex, servindo não apenas como instrumento de análise, mas também como uma ferramenta política, visando rejeitar o determinismo biológico implícito no uso do termo sexo. Contudo, a autora ressalta que isso não significa uma negação da constituição do gênero sobre corpos sexuados, ou seja, a biologia não é negada, mas ocorre uma ênfase na construção social e histórica produzida sobre as características biológicas. Dessa forma, o gênero é tratado como um dos elementos que constitui as identidades dos sujeitos, que a autora define como plurais, múltiplas, contraditórias e que se transformam por meio de nossas práticas sociais.

Louro (1997) argumenta que, na compreensão de gênero, a prática social se direciona aos corpos. Nessa perspectiva, gênero é o modo como as características sexuais são compreendidas, representadas ou trazidas para a prática social, tornando parte do processo histórico. Para a autora, é por meio das relações sociais que os gêneros são construídos e, através dessas relações, ocorrem desigualdades sociais entre os gêneros que são justificadas não devido às diferenças biológicas, mas nos arranjos sociais, nas condições de acesso aos recursos da sociedade e nas formas de representação.

A maioria dos discursos sobre gênero incluem as questões de sexualidade de alguma forma (LOURO, 1997). Foucault ([1977] 1994) conceitua sexualidade como um dispositivo que "fala" a verdade sobre o sujeito e o sexo como algo relativo à sua esfera privada. O autor considera a sexualidade como uma "invenção social”, por se constituir dos múltiplos discursos acerca do sexo que regulam, normalizam e instauram "verdades" universais sobre ele. 
Por meio dos estudos queer, Louro (2000b) analisa historicamente como se proliferaram os discursos sobre sexualidade e a necessidade da distinção entre homossexualidade e heterossexualidade. A partir da segunda metade do século XIX, a norma heterossexual foi produzida, reiterada e tornada compulsória por meio das proclamações de diversos grupos sociais (médicos, pensadores, moralistas). Essa norma, que toma a heterossexualidade como universal e os discursos que descrevem a homossexualidade como situação desviante, foi denominada posteriormente pelo teórico americano Michael Warner (1993) como heteronormatividade.

Na próxima seção, faremos uma breve discussão sobre a Análise Crítica do Discurso e a Linguística Sistêmico-Funcional, com ênfase nos significados do discurso propostos por Fairclough (2003a).

\section{Análise crítica do discurso}

O foco principal da ACD faircloughiana é a mudança social a partir da discursiva, considerando que ambas se implicam mutuamente. Além disso, propõe-se a discutir e problematizar os aspectos considerados opacos dos discursos no que tange às desigualdades sociais, o que destaca seu caráter emancipador.

Fairclough (2003a) argumenta que o termo discurso pode ser compreendido em concepções diferentes, no singular e no plural. No primeiro, 'discurso' é tido como um substantivo abstrato, visto como um elemento das práticas sociais. Em uma perspectiva mais concreta, tratado como um substantivo contável e com base nos conceitos foucaultianos, o termo discurso é utilizado para se referir aos modos diferentes de significar e de estruturar áreas do conhecimento e práticas sociais a partir de uma perspectiva particular (FAIRCLOUGH, 2003a), como o discurso médico, o discurso feminista e o discurso midiático.

No tópico a seguir, explanamos acerca dos significados do discurso conforme propõe Fairclough (2003a).

\section{Significados do discurso}

Para Fairclough (2003a), o discurso figura por meio de três formas como parte das práticas sociais que ocorrem através da relação entre texto e eventos, denominadas como significados acional, representacional e identificacional. Cada um desses significados corresponde a um modo de interação entre discurso e prática social (modos de agir, de ser e de representar) e também a um elemento que compõe as ordens do discurso (gênero, discursos e estilos).

Segundo Fairclough (2003a), é por meio de formas discursivas e/ou não discursivas que os agentes sociais agem em eventos sociais e esse modo de agir e interagir socialmente em um aspecto discursivo é denominado de gênero. Através do significado acional, podemos analisar como os significados estão servindo para uma determinada ação, por meio de textos e de sua localização e realização em eventos, práticas e estruturas sociais.

O significado representacional de textos é o que se relaciona com discurso sendo tratado, segundo Fairclough (2003a), como uma forma particular de representar alguma parte do mundo, que pode ser observado, identificado e 
nomeado por meio de análises, como o discurso neoliberal e o discurso machista. A interdiscursividade é uma das categorias de análise do significado representacional. Por meio dela, é possível observar que um mesmo fato pode ser apresentado por meio de diferentes discursos, em uma relação dialógica que pode ser de harmonia ou de contradição, de cooperação ou antagonismo. $\mathrm{O}$ vocabulário é considerado o mais evidente dos traços para diferenciar discursos, pois, segundo Resende e Ramalho (2006), os diferentes discursos lexicalizam o mundo de formas diferentes.

O terceiro significado apresentado por Fairclough (2003a) relaciona-se aos aspectos discursivos dos modos de ser (estilos), juntamente aos procedimentos de identificação no texto, que ocorrem não apenas linguisticamente, mas também por meio de uma relação dialética entre discurso e prática social. As constantes mudanças na sociedade contemporânea têm provocado alterações nas identidades dos agentes sociais, que favorecem um desenvolvimento de autopercepção identitária (GIDDENS, 1991; 2002), coexistindo com a fragmentação das identidades (HALL, 1999).

A Linguística Sistêmico-Funcional contribuirá na análise dos dados apresentados nesse artigo por meio da identificação dos processos de transitividade selecionados pelos autores dos enunciados. Dessa forma, são apresentados conceitos relacionados à LSF na próxima seção deste trabalho.

\section{Linguística sistêmico-funcional}

A Linguística sistêmico-funcional (LSF) de Halliday (1994) é considerada um sistema de significados, ou seja, um sistema que apresenta os padrões semânticos que surgem devido às necessidades dos falantes de interpretar a experiência humana, pensando e agindo com a língua. Nessa perspectiva, a linguagem é social, pois ela só ocorre se estiver imbricada na sociedade.

Para a LSF, os componentes principais do significado na língua são componentes funcionais. Sua principal preocupação é compreender e descrever a linguagem como um sistema de comunicação humana. Nessa perspectiva, duas possibilidades alternativas organizam a língua: a cadeia (o sintagma) e a escolha (o paradigma). É importante ressaltar que o termo sistêmica relacionase às redes de sistemas da linguagem (transitividade) e o termo funcional referese às funções da linguagem que produzem significados.

A LSF se associa a três metafunções: interpessoal, ideacional e textual, que ocorrem de forma simultânea nos textos. Devido a elas, identificamos como o discurso é organizado. Para Papa (2008), essas três metafunções fornecem explicações do uso da língua partindo das necessidades e dos propósitos do falante em determinados contextos de situação.

A metafunção interpessoal é a característica que a linguagem tem de estabelecer trocas e relações entre interlocutor e receptor, cujos papéis são definidos por meio da interação. Por sua vez, a metafunção ideacional se relaciona com a possibilidade que a linguagem oferece de falar sobre o mundo, transmitindo e expressando ideias. Por fim, a função textual relaciona-se à variável de registro (Modo) e se expressa por meio da ordem dos constituintes da oração, atribuindo significado à mensagem.

Em Analysing discourse (2003a), Fairclough propõe uma articulação entre essas três metafunções e os conceitos de gênero, discurso e estilo. Para o autor, 
o significado acional aproxima-se da função interpessoal e incorpora a função textual; o significado representacional corresponde à função ideacional e o significado identificacional incorpora traços da função interpessoal. Esses significados podem ser encontrados de forma simultânea em textos, pois estão dialeticamente relacionados, ou seja, cada um internaliza o outro.

Para a LSF, a transitividade é entendida como a categoria gramatical que se refere à metafunção ideacional (HALLIDAY, 1994). Na compreensão em que a experiência humana é tratada como um fluxo de eventos ou acontecimentos, a transitividade é a responsável pela materialização dessas atividades por meio dos processos (CUNHA e SOUZA, 2011).

Os principais papéis da transitividade ocorrem por meio dos processos (verbos), participantes (substantivos) e circunstâncias (advérbios). No sistema da transitividade, existem três processos principais (materiais, mentais e relacionais) e três processos secundários (comportamentais, verbais e existenciais).

Neste trabalho, a LSF dará suporte à identificação de alguns elementos lexicais considerados relevantes para a pesquisa, como os processos utilizados pelos dois entrevistados para expor suas crenças, posicionamentos e visões de mundo, sobre questões de gênero, sexualidade e preconceito.

\section{Formação crítico-reflexiva de professores/as}

Para Pennycook (1998), ensinar de forma crítica é romper com o positivismo e estruturalismo do conteúdo ministrado e buscar explorar seu caráter histórico, político e cultural. Devido a sua preposição da reflexividade fundamentada no processo reflexão-ação-reflexão, que visa a formação da consciência política, o teórico brasileiro Paulo Freire é considerado um dos precursores do ensino crítico. O autor afirma que a "capacidade de agir e refletir é a condição primeira para que os sujeitos assumam atitudes comprometidas com transformação" (FREIRE, 2002, p. 17). O autor defende que a reflexão do sujeito sobre si, sobre o seu estar e suas ações sobre o mundo permitem ultrapassar limites que muitas vezes lhe são impostos, adotando, então, ações comprometedoras e políticas.

Segundo Contreras (2002), a reflexão não é capaz de abordar várias questões que vão além da sala de aula, pois, apesar do/a docente ter uma responsabilidade primordial no processo de ensino, muitas questões dependem também de questões políticas educacionais e sociais. Com isso, é necessário que o/a professor/a se conscientize do lugar que ocupa e da importância que tem na sociedade, se tornando, então, um/a professor/a crítico-reflexivo/a (ALARCÃO, 1996).

Barros (2010; 2015) afirma que a relevância do pensamento social crítico proporcionou reflexões sobre a teoria crítica da sociedade moderna, o que permitiu aos/às educadores/as (de línguas) reflexões sobre o papel do/a docente como agente crítico/a de mudanças na escola e na comunidade escolar, considerando os reais problemas que ocorrem nessa esfera da vida cotidiana.

\section{Contexto da pesquisa}


Os dados analisados neste trabalho foram coletados em dois momentos: durante um curso de formação continuada sobre diversidades e em entrevistas semiestruturadas realizadas após ele. O curso teve como título "Diversidades e opressões no contexto escolar" e foi iniciado no mês de março de 2015, com um total de 40 horas. Foi ministrado por um dos pesquisadores, com o apoio da Secretaria de Educação do Estado de Mato Grosso (SEDUC-MT), por meio do Centro de Formação de Professores de Barra do Garças-MT (CEFAPRO). Foram um total de 20 encontros divididos em dois semanais de duas horas cada, que ocorreram na Escola Estadual Getúlio Vargas (Cocalinho-MT), das 17:0oh às 19:ooh, durante os meses de março, abril e maio.

Selecionamos para esta análise gravações de uma entrevista semiestruturada com o docente Elvis (nome fictício). O objetivo dessa escolha é verificar possíveis reflexos dos estudos acerca de temas como homossexualidade e homofobia, assim como, perceber quais discursos prevalecem em sua fala, por meio da categoria interdiscursividade do significado representacional do discurso (FAIRCLOUGH, 2003a). Elvis é graduado em Pedagogia, tem 40 anos e é professor de reforço dos/as alunos/as com dificuldade de aprendizagem do Ensino Fundamental (segunda fase). É católico, casado com uma mulher também professora pedagoga - e tem três filhos.

Durante a discussão acerca de gênero e sexualidade nos encontros do curso, os/as professores/as comentaram sobre um morador de Cocalinho-MT conhecido como Pintado. Ele é heterossexual, casado, tem dois filhos, trabalha de mecânico e costuma usar trajes femininos em passeios noturnos com sua família. Após o término do curso de formação continuada, realizamos uma breve entrevista semiestruturada com esse mecânico. Procuramos analisar quais discursos prevalecem em seus enunciados ao falar sobre gênero, homossexualidade e homofobia.

\title{
Análise de dados
}

Durante os encontros em que os/as professores/as participantes do curso debatiam sobre o texto "Gênero, Sexualidade e Educação: uma perspectiva pósestruturalista" (LOURO, 1997), era recorrente os/as docentes citarem o mecânico Pintado. Enquanto alguns/as comentaram que não compreendiam o porquê de ele se vestir com roupas femininas, pois isso poderia gerar constrangimento para a sua esposa, filhos e familiares, outros - em menor número - argumentavam que não viam problema nisso. Em um determinado momento, Elvis fez o seguinte comentário:

\begin{abstract}
Recorte o1
Eu procuro entender o que leva um homem a se vestir de mulher ou a ser gay, sabe? Mas isso não afeta o caráter dele de forma alguma. Acredito que muito tem a ver com o psicológico, é... Com algum trauma que o cara teve para ele querer ser uma mulher ou algo assim, porque não é normal. Só que isso não interfere no caráter da pessoa, entende? Por isso eu acho que não deve ter preconceito porque devemos ver o caráter de cada um e não o que a pessoa usa ou faz.
\end{abstract}

Para Halliday (1994), os processos mentais são aqueles que demonstram as crenças, desejos e valores dos autores. Eles são utilizados para expressar as experiências de sentir, a cognição e a afeição do Experienciador (o participante consciente que experimenta um sentir) sobre o Fenômeno (fato que é sentido, 
percebido ou compreendido). No recorte 01, o professor Elvis utiliza diferentes processos mentais ('procurar', 'entender', 'querer', 'ver') para expor suas crenças sobre gênero e seus desejos acerca do tratamento que as pessoas que fogem do padrão heteronormativo devem receber.

No recorte supracitado, o Experienciador Elvis (apresentado em seu enunciado por meio do pronome 'Eu') utiliza os processos mentais de cognição 'procuro' e 'entender', que são escolhas no sistema paradigmático da língua para expor a busca do falante em compreender o que leva um homem heterossexual ser do gênero feminino. As estruturas 'se vestir de mulher' e 'ser gay', situados após os processos principais do enunciado, caracterizam como o Fenômeno, ou seja, aquilo que o Experienciador tenta compreender.

Observa-se que Elvis relaciona gênero e sexualidade com o caráter do ser humano, por meio da estrutura 'não afeta o caráter dele de forma alguma'. Em seu enunciado, percebe-se a presença de uma crença que constitui suas práticas sociais: a busca pelo respeito do indivíduo independente de sua forma de ser. Ele ressalta essa sua maneira de lidar com o outro por meio do modalizador 'devemos' e o processo mental de percepção 'ver', ao afirmar 'devemos ver o caráter de cada um'. Ao utilizar os processos na primeira pessoa do plural, Elvis aponta que seu desejo seja algo social, realizado por todos os indivíduos, inclusive por ele.

Outra crença expressa na fala do professor é a relação do gênero de um indivíduo com possíveis traumas que o mesmo pode ter sofrido em algum momento de sua vida. Para isso, ele utiliza expressão modalizadora 'acredito' com o enunciado 'com algum trauma que o cara teve'. Para Borges (2009), embora não façam parte da maioria dos/as homossexuais, experiências de abusos sexuais na infância costumam ser um fator importante no desenvolvimento de ordem sexual e afetiva. Todavia, Borges ressalta que, apesar do que se costuma afirmar, essas crianças não se tornam homossexuais devido ao abuso, mas são abusadas porque são homossexuais. Nessa perspectiva o problema não está na homossexualidade em si, mas na experiência traumática vivida pelo indivíduo homossexual.

Apesar de demonstrar respeito aos indivíduos independentemente de seus gêneros e sexualidades, evidenciando a importância de levarmos em consideração o caráter das pessoas, Elvis revela o discurso heteronormativo em sua fala, ao compreender o gênero feminino em um homem como uma anormalidade. Assim, utiliza-se do advérbio de negação 'não' com o processo relacional 'ser' para dizer que o fato de um homem se vestir de mulher 'não é normal'.

Para Halliday (1994), os processos relacionais são utilizados para definir, classificar, caracterizar e generalizar visões particulares das experiências vividas. São divididos em processos relacionais atributivos e identificados, com a presença de dois participantes: Portador e Atributo (atributivos) e Característica e Valor (identificados). No enunciado supracitado, o processo relacional 'é' se caracteriza como identificador, pois o falante relaciona um significado de anormalidade (Valor) ao fato de um indivíduo 'querer ser mulher ou algo assim' (Característica).

O discurso homofóbico não está presente na fala do professor; entretanto, tratar a homossexualidade ou aquilo que foge dos padrões heterossexuais como algo anormal pode contribuir para que discursos hegemônicos prossigam nas práticas discursivas, culminando em possíveis ações de discriminação. 
Esse diálogo conflituoso de discursos presente na fala de Elvis faz parte do posicionamento de muitos docentes em todo o país. Segundo Seffner (2009), a ideia de inclusão das diversidades é quase unânime no discurso pedagógico, entretanto, ela se depara com preconceitos, manifestações de estigma e discriminações contra alunos que demonstram orientação diversa da heterossexual, portadores/as de HIV, dentre tantos outros, por parte dos próprios docentes.

Em relação ao habitante de Cocalinho que é heterossexual e se veste com trajes femininos, conhecido como Pintado, Elvis demonstrou interesse no caso durante as discussões no curso. Ao perceber isso, o professor-formador e pesquisador sugeriu que ele conversasse com esse mecânico e o conhecesse melhor. Como Elvis ressaltou que não compreendia o porquê de Pintado, apesar de ser heterossexual, se vestir com roupas femininas, consideramos relevante realizar um diálogo com Pintado, uma vez que poderia ajudá-lo a entender melhor os conceitos estudados durante o curso.

$\mathrm{Na}$ semana seguinte, Elvis comentou que teve uma longa conversa com Pintado em um bar da cidade. Ele relatou que, a todo instante, seus/suas alunos/as passavam em frente ao estabelecimento e ficavam olhando os dois conversando, demonstrado expressões de surpresa e espanto. Sobre esse encontro, o professor relatou:

\begin{abstract}
Recorte 02
A visão que eu tive dele é outra porque ele simplesmente só se veste de mulher. Quando você começa a olhar ele por esse olhar diferenciado, é muito interessante. Ele tem uma personalidade que... Se você olhar para ele com olhar diferenciado para ele, você irá perceber algumas coisas que passam despercebidas e que a sociedade não consegue ver devido ao preconceito.
\end{abstract}

Em sua fala, Elvis expressa a opinião que teve de Pintado, utilizando-se do processo relacional identificador 'ser' para afirmar: 'a visão que eu tive dele é outra'. Nesse enunciado, a Característica a compreensão que o falante tinha de Pintado e o Valor é o termo 'outra'.

É possível perceber que o falante possuía a crença de que o fato de um homem se vestir com roupas femininas o caracterizava como homossexual, não compreendendo, então, as distinções de gênero e sexualidade. Com o advérbio 'simplesmente', ressalta a condição do mecânico de se vestir dessa forma, mas não possuir atração por outro homem.

Elvis utiliza duas vezes o adjetivo ‘diferenciado’ para qualificar a visão que teve de Pintado após esse encontro. Novamente, o docente utiliza processos mentais de percepção para expor sua apreciação humana. Com o processo mental de percepção 'perceber', ele comenta que o preconceito faz com que 'algumas coisas passam despercebidas', afirmando, com o modalizador 'consegue' e o processo mental de percepção 'ver', que esse sentimento opressor impossibilita a sociedade de identificar características em um indivíduo além do que ele aparenta ser. $\mathrm{O}$ adjetivo 'interessante' expressa a mudança de visão que Elvis começou a ter após esse diálogo.

Percebe-se em toda a fala de Elvis o discurso de percepção das diversidades, em que elas começam a ser entendidas de forma emancipada a partir do momento em que ocorre uma abertura para a sua compreensão, baseada em princípios de igualdade e respeito. O sujeito prosseguiu seu relato afirmando: 
Eu perguntei muitas coisas para ele e ele respondeu com uma convicção que você percebe sinceridade nas palavras dele. Eu falei: você não é hipócrita porque muitas vezes a hipocrisia social esconde muitas coisas, inclusive sua personalidade que é absolutamente normal.

O processo verbal 'perguntar' é utilizado pelo sujeito para narrar a conversa que teve com Pintado. Para Halliday e Matthiessen (2004), os processos verbais contribuem para a criação da narrativa, tornando possível estabelecer passagens dialógicas tanto em narrativas escritas quanto em relatos orais, como ocorreu nos dados analisados neste trabalho.

Por meio do processo mental de percepção 'perceber', ele relata que observou serem verdadeiras as respostas recebidas do mecânico, pois afirma que ele 'respondeu com convicção'. O sujeito fez uma análise sobre a personalidade de Pintando ao afirmar 'você não é hipócrita', justificando que a 'hipocrisia social esconde muitas coisas'. Nesse enunciado, o processo relacional selecionado por Elvis é atributivo, pois ele qualifica o Portador Pintado (apresentado por meio do pronome 'você') como uma pessoa não hipócrita (Atributo).

Na instância discursiva analisada, é possível perceber um início de reflexão em relação à visão que o falante possuía acerca de homens que se vestem com trajes femininos. Se antes ele afirmava que o fato de um heterossexual vestir roupas femininas ocorria devido a transtornos psicológicos, afirmando que isso 'não é normal' (Recorte o1), agora ele expressa visão contrária a esse posicionamento. Novamente, é possível identificar um discurso de percepção das diversidades pautado no respeito.

$\mathrm{Na}$ entrevista realizada ao fim do curso, Elvis comentou novamente sobre seu contato com Pintado:

\begin{abstract}
Recorte 04
Acho ele de uma sabedoria muito grande. Eu jamais me imaginaria conversando com alguém assim, sabe? Um cara que se veste daquela forma. Já encontrei com ele outras vezes depois daquele dia e vamos acabar sendo amigos, porque ele é um cara muito gente boa. Nunca fui de ter muito papo com gays, mas confesso que as leituras me despertou inclusive curiosidade de conhecê-los mais, buscar ver o outro lado, sabe? Como eles conseguem ser felizes mesmo com tanto preconceito. São vencedores para mim.
\end{abstract}

O modalizador 'acho' é utilizado para indicar a opinião do docente sobre Pintado, em que ele afirma considerar o mecânico uma pessoa sábia. Elvis é enfático ao afirmar que não se via tendo contato com alguém como Pintado, que é heterossexual e se veste com roupas femininas.

Por meio do advérbio de negação 'jamais' e do processo mental de cognição 'imaginar', ele expressa um posicionamento presente em nossa sociedade heteronormativa: o distanciamento das pessoas heterossexuais em relação às homossexuais. O uso do advérbio de negação 'jamais' também indica que esse hábito de conversar com pessoas como Pintado não fazia parte da vida do professor.

Borrillo (2009) argumenta que essa postura é um dos fatores que compõem a homofobia. Segundo o pesquisador, ela não é um problema apenas para os homossexuais, mas também para os heterossexuais, pois os impede de terem relações íntimas entre qualquer sexualidade masculina, seja heterossexual ou homossexual. Fatores como competição, medo da fraqueza, controle dos sentimentos constituem elementos modalizadores da forma de ser masculina. Desse modo, o distanciamento em relação aos homossexuais aparece 
como um dos mais importantes elementos da (auto)construção da masculinidade.

O professor afirma que afirma que existe a possibilidade de ambos se tornarem amigos, pois o professor considera o mecânico 'um cara muito gente boa'. Nesse enunciado, ele menciona Pintado por meio da expressão 'cara' (Portador) e a visão que possui do mecânico após seu contato com ele por meio da expressão 'muito gente boa' (Atributo). Dessa forma, o processo 'ser' que antecede essa expressão é considerado relacionado atributivo.

Com o advérbio de negação 'nunca', ele enfatiza que não possuía contato com 'gays'. Todavia, Elvis argumenta que, devido aos textos discutidos durante o curso, sentiu-se motivado a conhecer pessoas homossexuais, ou seja, sentiu-se inspirado a 'buscar ver o outro'. Por o docente apresentar um desejo seu despertado por meio do contato com Pintado, ele selecionou o processo mental de cognição 'ver'.

O discurso de emancipação está presente na fala do sujeito por ele demonstrar ruptura de uma postura que não se permitia ter ('jamais me imaginaria conversando com alguém assim'). Para Bhaskar (1998), os mecanismos geradores de problemas sociais podem ser removidos e a emancipação deve passar pela transformação dos próprios agentes ou participantes.

A iniciativa de Elvis de procurar o mecânico para conversar, de buscar entendê-lo e de se sentir motivado a ter contato com pessoas homossexuais aponta para a emancipação argumentada por Bhaskar (1998), pois a mudança de atitude do professor não ficou apenas no plano da consciência, mas houve agentividade, pois o docente convidou o mecânico para uma conversa.

No enunciado, observa-se o discurso de reconhecimento e valorização dos/as homossexuais, pelo fato de o sujeito compreender o preconceito existente contra uma classe inferiorizada socialmente e romper posicionamentos de distanciamento. Junqueira (2009) afirma que, ao propiciarmos novas possibilidades de ver e perceber indivíduos e grupos até então alvo de estereótipos e preconceitos, a desmistificação de representações torna-se fundamental para a desconstrução de mecanismos de percepção de crenças que legitimam relações de forças extremamente assimétricas.

A iniciativa de Elvis de buscar não apenas compreender Pintado, mas fazer contato com o mesmo, abrindo inclusive possiblidade de construir uma amizade, denota uma desestabilização de pensamentos que o mesmo possuía em relação aos homossexuais, mesmo o mecânico não sendo um.

$\mathrm{O}$ discurso de reconhecimento e valorização da diversidade presente nos enunciados de Elvis pode ensejar novas formulações do que antes era pensado de forma naturalizada, como também novas formas de aprender, de agir, reconhecer, pensar e sentir.

Recentemente, conseguimos realizar uma entrevista com Pintado, a fim de compreender melhor a sua identidade de gênero e sexual. Ao ser questionado sobre qual sexualidade compreende ter, o mecânico concedeu a seguinte resposta:

\footnotetext{
Recorte 05

Eu sou hétero e sempre me considerei, sabe? Nunca senti vontade de ficar com homens e nem nada disso. No colégio, os caras falavam que eu era gay e tinha vezes que eu até ficava pensando que eu seria mesmo ou bi. Mas, eu olhava para os caras e não sentia vontade alguma de ficar com eles.

Márcio: E com as garotas? Você sentia atração?

Pintado: Nossa, muito. E não perdia tempo. Se desse bola, eu ficava mesmo.
} 
Em seu enunciado, o mecânico utiliza-se do processo relacional atributivo 'ser' para expor sua sexualidade. Ao afirmar 'eu sou hétero e sempre me considerei', o uso do advérbio de frequência 'sempre' com o processo verbal 'considerar' indicam um alto grau de certeza do individuo em sua fala, mostrando que ele não possui dúvidas acerca de sua identidade sexual. Ele reforça esse posicionamento no enunciado seguinte, por meio do advérbio de negação 'nunca' e o processo mental de percepção 'sentir', ao expressar que, em momento algum, se sentiu atraído por alguém do mesmo sexo.

Pintado relata que, durante o período que estudou em um colégio, seus colegas comentavam que ele era homossexual ('os caras falavam que eu era gay'), por meio do processo verbal 'falavam'. Esse fato fazia com que o mecânico repensasse sua sexualidade. Em sua instância discursiva, é utilizado o processo mental 'pensar' para expor esses momentos de reflexão. Contudo, por meio dos processos mentais de percepção 'olhar' e 'sentir', Pintado afirma que observava os rapazes e não sentia atraído por eles. $\mathrm{O}$ uso recorrente de processos mentais no fraseado de Pintado indica uma necessidade dele de expressar desejos que possui acerca do outro ('olhava para os caras e não sentia vontade').

Com o objetivo de compreender melhor a formação de sua sexualidade, questionamos o mecânico se ele sentia atração por garotas. De forma enfática, Pintado afirma que possuía desejos pelo sexo oposto, ao utilizar da interjeição 'nossa' e o advérbio de intensidade 'muito'. O mecânico comenta que, se uma mulher demonstrasse interesse, eles teriam algum relacionamento ('eu ficava mesmo').

Ao analisarmos interdiscursivamente, observamos a presença do discurso de reconhecimento da sexualidade. O mecânico se reconhece como heterossexual por meio de afirmações sem o uso de modalizadores que indicam um baixo ou médio grau de afinidade ('acho', 'acredito'). Entretanto, esse discurso dialoga de forma conflituosa com o discurso de bissexualidade. Apesar de ele afirmar que sempre se considerou heterossexual, o mecânico reconhece que chegou a pensar que era homossexual ou bissexual, devido aos comentários feitos por seus colegas de escola.

Com o objetivo de dialogar sobre o gênero do mecânico, questionamos Pintado sobre a época em que começou a vestir trajes femininos.

\begin{abstract}
Recorte o6
Foi quando vesti uma roupa da minha mãe. Estava na sexta série. Eu achava massa ficar de vestido dentro de casa. Minha mãe não se importava. Quando virei adulto, decidi usar para sair a noite. Me sinto bem, gosto disso, sabe? Minha esposa me conheceu assim e ela também não se importa. É eu. Faz parte do que eu sou.
\end{abstract}

Por meio do processo material 'vestir', Pintado relata um costume que começou em sua infância, quando ele começou a vestir roupas de sua mãe. Para Halliday (1994), os processos materiais externam uma ação presente que envolve, pelo menos, um Ator (participante). Nesse caso, o mecânico é o Ator realiza uma ação observável ('vesti uma roupa da minha mãe').

Pintado prossegue seu relato utilizando processos materiais para indicar ações que realizavam nessa etapa de sua vida e que influenciaram a construção de sua identidade sexual e de gênero. Os processos materiais 'decidir' e 'usar' são selecionados pelo mecânico para expressar a sua mudança de atitude na fase adulta, quando começou a se vestir com trajes femininos não apenas em seu lar, mas também em ambientes externos. 
Os processos mentais de percepção 'sentir' e de afeição 'gostar', com o termo 'bem', presentes em seu relato apontam para uma satisfação do mecânico com a prática de usar trajes femininos. Pintado comenta que sua esposa, assim como sua mãe, não se importa de ver o marido utilizando tais roupas. $O$ mecânico é enfático ao afirmar que essa característica integra sua identidade (de gênero): 'faz parte do que eu sou'. Nesse fraseado, o processo relacional 'ser' possui função atributiva por qualificar o Portador com uma característica específica.

Em seu relato, Pintado prossegue com o discurso de reconhecimento de sua identidade de gênero. Com base nos estudos queer, é possível observar que o fato de Pintado utilizar roupas femininas durante muitos anos contribuiu para a formação de sua identidade de gênero. Butler (1993) sugere que o gênero é uma construção social, histórica e contingente. Dessa forma, as experiências de um indivíduo ao longo da sua vida ajudam a constituir o seu gênero que, apesar de relacionar com a sexualidade do sujeito, não é determinado especificamente por ela. Por isso, um homem heterossexual pode ter uma identidade de gênero feminina, como é o caso de Pintado.

Sobre a compreensão que possui acerca de seu gênero, Pintado comentou:

\begin{abstract}
Recorte 07
Eu sei que sou do gênero feminino. Me identifico, sabe? Gosto de arrumar as unhas, passar batom, comprar meus tamancos (risos). Mas na hora de beijar na boca, fazer amor, sou mais homem que a maioria (risos). Vejo que sou heterossexual porque não me interesso sexualmente pelos caras. Minha forma de vestir não define minha sexualidade.
\end{abstract}

Com o processo relacional atributivo 'ser', Pintado reconhece sua identidade de gênero como feminina. Ele justifica tal afirmação por meio do processo do processo mental de afeição 'gostar' e dos processos materiais 'passar' e 'comprar', comentando atos identificados socialmente como femininos: 'arrumar as unhas, passar batom, comprar meus tamancos'.

$\mathrm{O}$ uso da conjunção adversativa 'mas' indica uma ressalva em seu enunciado. Pintado comenta que se reconhece como heterossexual, pois, apesar de ser do gênero feminino, ele não possui atração por homens ('não me interesso sexualmente pelos caras').

Ao afirmar que sua forma de se trajar não define a sua sexualidade, Pintado traz em seu enunciado o discurso queer dialogando de forma harmônica com o discurso de emancipação. Por se posicionar de forma contrária a essa norma social, o mecânico demonstra ter um pensamento emancipado, não permitindo que tal compreensão heteronormativa o constranja a se vestir da forma que mais gosta e que o faz se sentir bem.

Em determinado momento da entrevista, o questionamos sobre o preconceito que possa sofrer por se vestir com trajes femininos. Pintado nos concedeu a seguinte resposta:

\footnotetext{
Recorte 08

Eu sempre sofri preconceito. Sou preto, pobre e ainda curto vestir que nem mulher. No colégio, isso me incomodava. Hoje, não mais. Se vejo que está passando dos limites, registro um B.O. na polícia. Mas hoje em dia quase não enfrento isso, sabe? Acho que a galera daqui já se acostumou. E também porque eu respeito todo mundo, aí acredito que retribuem com respeito também. Desfilei como musa do Araguaia na temporada e todo mundo amou (risos). Minha esposa achou o máximo.
} 
O mecânico utiliza o advérbio de frequência 'sempre' e o processo mental 'sofrer' para afirmar que o preconceito faz parte de sua rotina. Pintado justifica esse pensamento explicando que integra os grupos sociais considerados marginalizados socialmente devido ao preconceito que sofrem: negros/as, pobres e aqueles/as que desviam da norma heteronormativa. Sobre se incomodar com atos preconceituosos, Pintado comenta que apenas na fase em que estudou em um colégio isso o perturbava.

É possível observar que Pintado não se intimida perante o preconceito que sofre. Por meio do processo material 'registrar', o mecânico argumenta que denuncia o(s)/a(s) agressor(es)/as por meio de um boletim de ocorrência. Entretanto, Pintado afirma que, atualmente, ele não sofre muito preconceito na cidade em que vive (Cocalinho-MT), pois acredita que os/as moradores/as do município já se acostumaram com a sua forma de vestir.

É possível identificar o discurso de respeito ao próximo na instância discursiva de Pintado. O mecânico utiliza o modalizador de médio grau de afinidade 'acredito' para afirmar que compreende o respeito que recebe como uma retribuição da sua conduta respeitadora.

Pintado comenta sobre ter desfilado no concurso Musa do Araguaia, que ocorre anualmente no mês de julho, em Cocalinho-MT. Apenas mulheres podem se inscrever nesse concurso, porém, Pintado pediu que participasse do evento e o prefeito do munícipio aceitou que o mecânico também desfilasse. Esse fato foi noticiado pela imprensa da região de Barra do Garças-MT e divulgado em sites de grupos ativistas LGBT. Apesar de não ter sido finalista, os/as moradores/as de Cocalinho demonstraram apoio a Pintado ('todo mundo achou o máximo’).

Em relação às construções socioculturais dos sujeitos desta pesquisa, é possível observar que o gênero e a sexualidade dos interlocutores se manifestaram em seus discursos e práticas sociais. O fato de o docente ser homem, heterossexual e do gênero masculino contribuiu para o seu posicionamento inicial acerca da homossexualidade e da percepção sobre alguém que não segue as regras heteronormativas. Durante a construção de sua identidade de gênero e sexual, ele foi cercado de discursos e práticas que o levaram a ter essa compreensão de mundo, pois geralmente os discursos masculinos tendem a ver a homossexualidade como algo inferior, digno de deboche, resistência e/ou afastamento. Isso ocorre porque a homossexualidade é relacionada ao feminino, considerado também inferior pelo discurso machista. Esses mesmos discursos, proferidos pelos colegas de Pintado sobre sua sexualidade, o levaram a um auto-questionamento sobre sua identidade sexual que influenciou na construção de sua identidade, pois o fez perceber que, apesar de preferir vestir trajes femininos, ele não era homossexual.

\section{Considerações finais}

Por meio dos recortes analisados, observamos que a principal desestabilização ocorrida nas práticas discursivas de Elvis foi sobre a sua compreensão de identidade de gênero. É possível perceber que Elvis demonstrou um início de emancipação em seu posicionamento no fim do curso ao buscar interagir com um sujeito considerado "desviando" na norma heteronormativa. Para Bhaskar (2002), a emancipação passa obrigatoriamente 
pela autoemancipação, pois quanto mais livre um indivíduo se torna, mais sua ação tomará o rumo certo. Papa (2008) compreende emancipação como libertação, para a qual é necessário empreender trabalho e comprometimento a fim de poder mudar as estruturas sociais. A desestabilização do posicionamento de Elvis em relação às diversidades não esteve presente apenas em suas práticas discursivas, mas também em suas práticas sociais, pois ele buscou interagir com o "desviante".

Acerca do posicionamento emancipado de Pintado, percebe-se que o fato dele viver em um ambiente com familiares (mãe e esposa) que respeitam seu gênero, pode ter contribuído para sua aceitação e reconhecimento como um homem do gênero feminino. Apesar dos colegas de adolescência terem problematizado sua sexualidade, fazendo-o repensá-la, Pintando percebeu durante suas experiências que é heterossexual.

Por meio do curso ministrado, observamos que muitos/as professores/as reproduzem discursos que remetem à homofobia não por serem pessoas homofóbicas, mas por não terem tido a oportunidade de ler, estudar e problematizar questões de gênero e sexualidade. Muitas vezes, para que seja despertado o interesse por parte do/a docente, é importante que aconteça uma motivação externa, como ocorreu com Elvis, que decidiu, após as discussões realizadas nos encontros do curso, ter um diálogo com uma pessoa que não segue o padrão social de identidade de gênero heteronormativo.

Construir práticas de respeito e cidadania frente às diversidades sexuais é algo que não ocorre de forma rápida, mas por meio de constantes reflexões que contribuem para que posicionamentos considerados hegemônicos sejam desestabilizados. Sendo a escola um ambiente de construção da cidadania e de diálogos sobre assuntos sociais que estão presentes na vida de todos/as, avaliamos ser importante e necessário que mais cursos sobre identidades de gênero e sexuais sejam realizados no contexto escolar.

Uma formação docente pautada na compreensão de respeito ao outro, independentemente de sua identidade e permeada pelo sentimento de agentividade social, pode refletir-se em aulas que promovam o respeito às diversidades, não por meio de um trabalho unilateral de conscientização do outro, mas pelo diálogo construído na troca de saberes entre professor/a e aluno/a, aluno/a e aluno/a e comunidade escolar em geral.

\section{Referências bibliográficas}

ALARCÃO, Isabel. Formação reflexiva de professores: estratégias de supervisão. Portugal: Porto Editora, 1996.

BARROS, Solange Maria de. Formação crítica do educador de línguas: por uma política emancipatória e de transformação social. In: BARROS, Solange Maria de; ASSIS PETERSON, Ana Antônia de. (org.). Formação de professores de línguas: desejos e possibilidades. São Carlos: Pedro \& João, 2010.

Realismo Crítico e emancipação humana - contribuições ontológicas e epistemológicas para os estudos críticos do discurso. Coleção: Linguagem $e$ Sociedade. vol. 11. Campinas, SP: Pontes Editores, 2015. 
BHASKAR, Roy. Critical Realism. Essential Readings. In: Archer, M.; Bhaskar, Roy; Collier, A.; Lawson, T. e Norrie, A. Centre For Critical Realism. Londres: Routledge, 1998.

. From Science to Emancipation. Alienation and the Actuality of Enlightenment. Sage Publications. Londres: New Delhi, 2002.

BORGES, K. Terapia afirmativa: uma introdução à psicologia e à psicoterapia dirigida a gays, lésbicas e bissexuais. São Paulo: GLS, 2009.

BORRILlO, D. A homofobia. In: LIONÇO, T. DINIZ, D. (org.). Homofobia e Educação: um desafio ao silêncio. Brasília: Letras Livres: Ed. UNB, 2009.

BUTLER, J. Gender Trouble. Feminism and the subversion of identity. New York: Routlegde, 1990.

Routledge, 1993.

Bodies that Matter. On the discursive limits of "sex". New York,

CONTRERAS, J. Autonomia de professores. Trad. Sandra Trabuco Valenzuela, São Paulo. Cortez, 2002.

FAIRCLOUGH, N. Analysing discourse: textual analysis for social research. $\mathbf{1}^{\mathrm{a}}$ ed. Londres: Routledge, 2003a.

FOUCAULT, M. Le Jeu de Michel Foucault. In: Dits et écrits: 1954-1988, vol. 3. Paris: Gallimard, (1977) 1994.

FREIRE, P. Pedagogia do Oprimido. 32. ed. Rio de Janeiro: Paz e Terra, 2002.

GIDDENS, A. As Consequências da Modernidade. São Paulo: Ed. Unesp, 1991. . Modernidade e Identidade. Rio de Janeiro: Jorge Zahar Editor, 2002.

HALL, S. A identidade cultural na pós-modernidade. Rio de Janeiro: DP\&A, 1999.

HALLIDAY, M. A. K. An introduction to Functional Grammar. Londres: Edward Arnold, 1985.

1994. An introduction to functional Grammar. Londres: Edward Arnold, . MATTHIESSEN, C. M. I. M. Introduction to functional grammar. 3. ed. London Arnold, 2004.

JUNQUEIRA, R. Educação e Homofobia: o reconhecimento da diversidade sexual para além do multiculturalismo liberal. In: . Diversidade Sexual na Educação: problematizações sobre a homofobia nas escolas. Brasília: Ministério da Educação, Secretaria de Educação Continuada, Alfabetização e Diversidade, UNESCO, 2009. 
LOURO, G. L. Gênero, sexualidade e educação: uma perspectiva pósestruturalista. Petrópolis: Vozes, 1997.

O corpo educado: pedagogias da sexualidade. Belo Horizonte: Editora Autêntica, 2000.

PAPA, S. M. de B. I. Implicações para a prática docente reflexiva. O Professor Reflexivo em Processo de Mudança na Sala de Aula de Língua Estrangeira: Caminhos para a (auto) Emancipação e Transformação Social. Tese de Doutorado, LAEL - PUC/SP, 2005.

- Prática pedagógica emancipatória: $O$ professor reflexivo em processo de mudança. São Carlos (SP): Pedro \& João, 2008.

PENNYCOOK, A. A linguística aplicada dos anos 90: em defesa de uma abordagem crítica. In: SIGNORINI, I; CAVALCANTI, M. C. (org.). Lingüística aplicada e transdisciplinaridade. Campinas: Mercado de Letras, 1998.

RESENDE, V. de M.; RAMALHO, V. Análise do discurso crítica. São Paulo: Contexto, 2006.

SEFFNER, F. Equívocos e armadilhas na articulação entre diversidade sexual e políticas de inclusão escolar. In: JUNQUEIRA, R. Diversidade sexual na Educação: problematizações sobre a homofobia nas escolas. Brasília: $\mathrm{MEC} / \mathrm{Secad} /$ Unesco, 2009.

WARNER, M. Fear of a queer planet. Minneapolis: University of Minnesota, 1993. 